\title{
Effect of X-Ray Diffractometer Geometrical Factors on the Centroid Shift of a Diffractic Line for Stress Measurement
}

\author{
A.K. Singh and C. Balasingh \\ Materials Science Division, National Aoronatical Laboralow, Hangil \\ (Received 15 July 1970; in final form 20 simum 1971 )
}

\begin{abstract}
Dxpressions for the centroid shift of a diffraction lino duo to goomotxicul farterw have lum

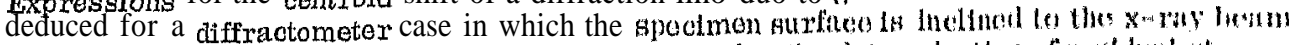

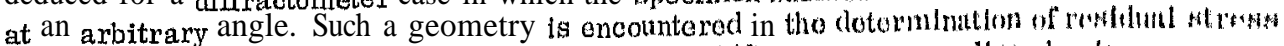
using a diffractometer. The effects of the centroid shift of a diffraction llne: lue (t)

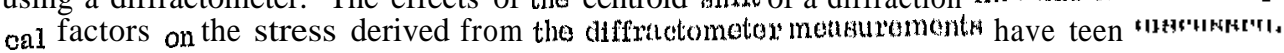

\section{INTRODUCTION}

In order to achieve high resolution and high count rate simultaneously, the modern diffractometers employ Bragg-Brentano focusing using a line source and a pair of Soller slits. The focusing conditions in practice deviate from the ideal in the following respects: (a) The specimen surface does not possess - the curvature required for focusing. (b) The $x$ rays penetrate into the specimen and diffracted beam of appreciable intensity occurs from the part of the specimen which does not lie on the diffractometer axis. (c) The source and the receiving slit have finite widths. (d) The incident beam has appreciable axial divergence. Further deviations from the ideal conditions may be caused by poor adjustment of the diffractometer with respect to the x-ray source and oi the specimen with respect to the diffractometer axis.

Any departure from the ideal conditions of focusing tends to distort the diffraction line profile. A measure of the position of a diffraction line is either the peak maximum or the centroid. In practice, determining the peak position of a line is easier than the centroid. However, mathematically, the effect of geometrical aberrations on the centroid can be more easily calculated since a diffraction maximum is the convolution ${ }^{2-5}$ of the profiles due to individual sources of aberrations; and in such a case the centroid is the sum of the centroids of the iadividual profiles,

The effect of these aberrations on a diffraction maximum has been considered ${ }^{1-19}$ in detail for the normal diffractometer condition.

However, for the determination of residual ${ }^{11}$ macrostresses in polycrystalline solids using an $\mathrm{x}$-ray diffractometer, it is essential to set the specimen making an arbitrary angle to the x-ray beam. In such a case, the diffracted beam is focused (Fig. 1) at a point whose distance from the diffractometer axis is given by

$$
R=S \sin (\theta-\psi) / \sin (\theta+\psi),
$$

where $S$ is the distance of the source from the dil fractometer axis, $B$ is the Bragg angle, and $\psi 18$ the angle between the specimen-surface normal and the reflecting-plane normal. In this paper, we have extended Wilson's ${ }^{13}$ method to derive expressions for the centroid shift of diff raction line due to yeom rical factors for a roomotiy shown in Fitr. 1. TC errors introduced by the centrold whit th the ex porimental values of strotacs have also bon dis cussed.

\section{BASIC EOUATTONS}

In this section, the batals approth of Wlinon's method ${ }^{13}$ as modified for thre protsent wase lats bo summarized.

\section{A. Choke of $\boldsymbol{A x} \mathrm{x}$}

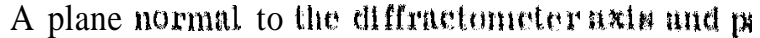
ing through the conter of gravity of the nawee a viewed from the nxis deflnow the equatorital plan The diverkence of the incldant $x$ tay lownt in th piano is termed equatorial diverisences. "Thw dive gence in a piano contalntak the dilf ratentometer and the center of the line noured la termod axd

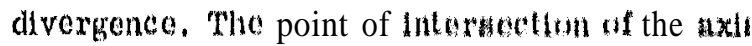
the equalional piano it taken ats the oritat of $\mathrm{cor}$ dinates (0 ln Fik, 2). The vector so (jolnung $A$ to in the equatorial plane defines an tdeat incident The tedeal diffructed ray is defuned by a verter i

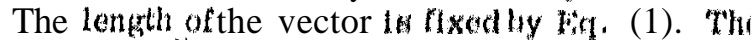
rection of $\mathbb{R} 1 \mathrm{~A}$ delined by the profetsten on the torlal plans of the line folnthy ote $\mathrm{H}^{\prime}$, the cont

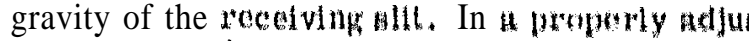
Instrument, $B^{\prime}$ will colncide with $\mathrm{ll}$.

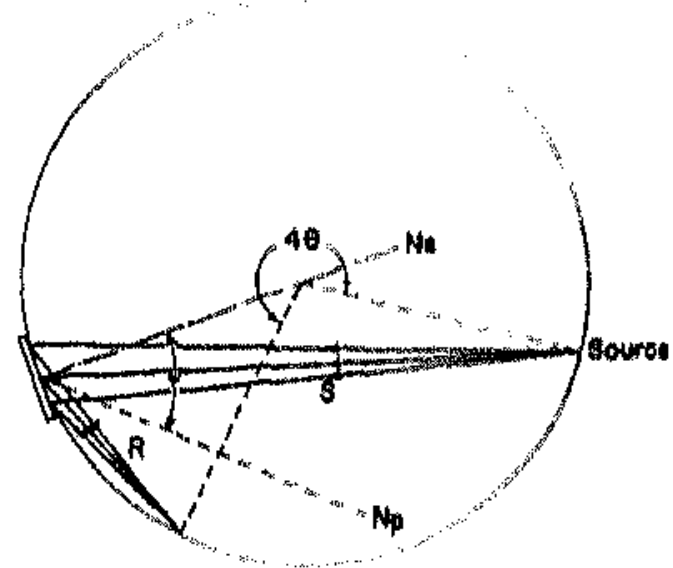

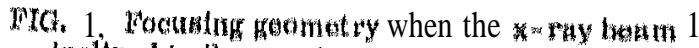

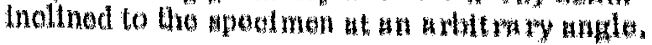




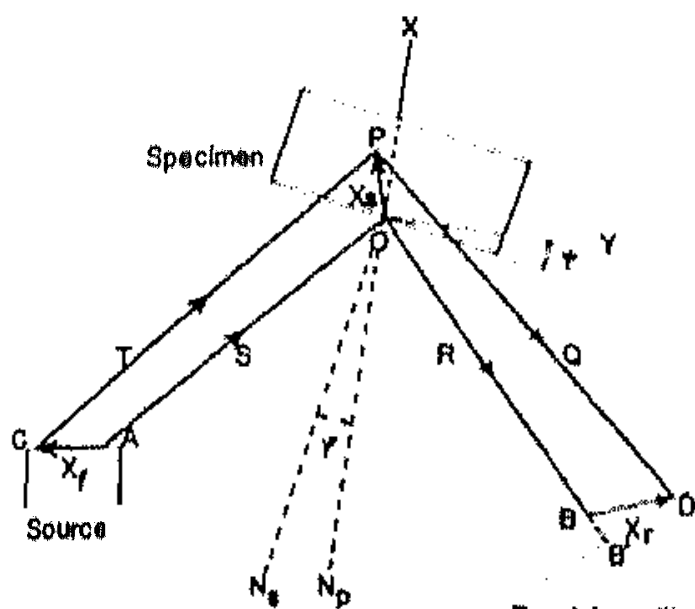

Racoluing all

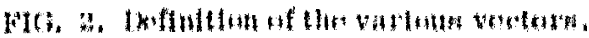

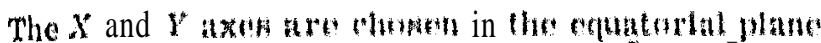

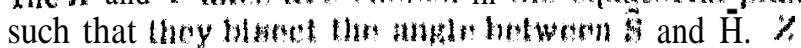

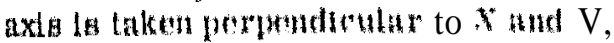

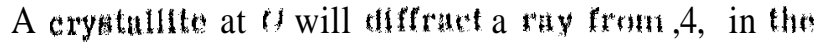

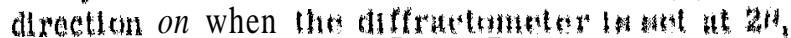

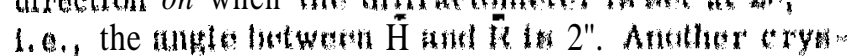

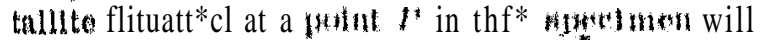

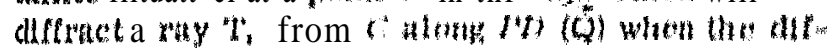

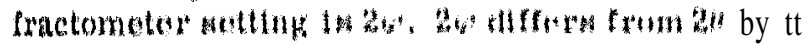

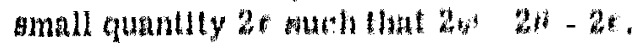

\section{Exprestion fus ar}

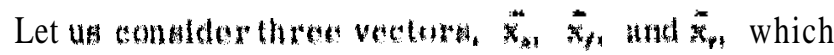

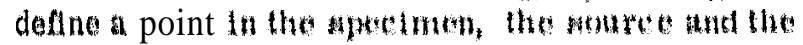

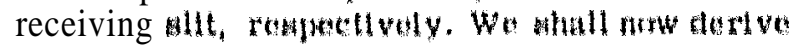

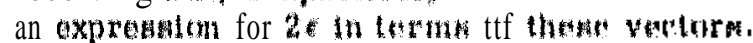
From Fy. $2 \mathrm{H}$ in cleme that

$$
\vec{x} \cdots+\vec{x}_{*}=\ddot{x}_{f}
$$

and

$$
\vec{Q}: \vec{n}+\tilde{x}_{r}-\tilde{x}_{4} \text {. }
$$

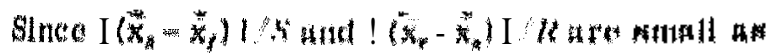

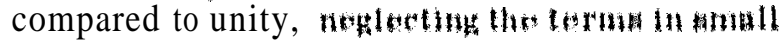

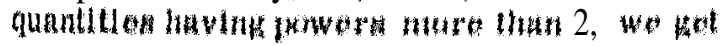

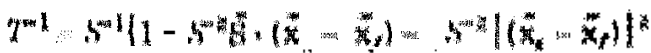

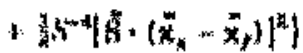

and

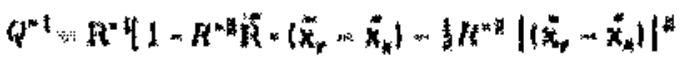

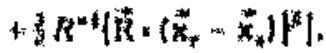

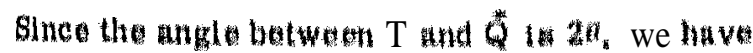

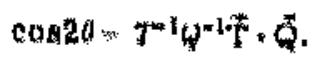

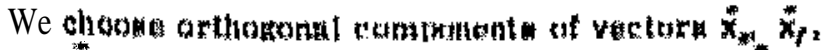
and $\vec{x}_{\mathrm{r}}$ ftg lollown. The compentente $x_{*}$ and $y_{*}$ of $x_{*}$ are in the equatoral plane and, renpect vely, per pendleutax and pallel to the apeetmen murace. $s_{f}$ and $y_{f}$ arc the components of $\bar{x}_{f}$ in the equatorint plane and, tespectively, parallel and perpentleutar to $5 . t_{r}$ and $y_{r}$ ato in the rquatoxialptane and, rem spesetively, thathes and perpendicular to Th. All the

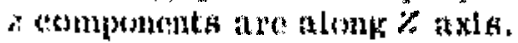

At this stake, it it neconsary to conalder the relative manntudes of the varicus vector components so that a meaningful approximation may be made. In practice, we have the following conditions govern on ing the delative marnitudes of the components of the vectore $x_{s 1} \quad x_{n}$ and $x_{r}$ :

(a) since the X-ray beam Is stromply absorbed in the mereimon, the polnta with laxpo $x$ do not contribute mperectably to the diffracted intensty and thus only the pountw with $x_{n}-y_{A}$ and $z_{a}$ need be considered.

(b) Normally, a llne sourea la used with powder didractomator. "Tha use of the Soller sllt limite the offective value of 2, and $1 \mathrm{~s}$ of the order of the bepa

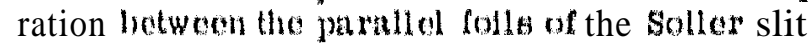
(atbent $0.5 \mathrm{~mm}$ ). The focal spot $1 \mathrm{H}$ normally $1 \times 10$ $\mathrm{mm}$ and when it is viowed at a takentf antel about

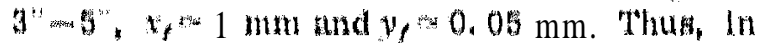

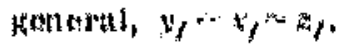

(v) Similar ttrpmentd show that $y_{r} \cdot z_{r}$ and $v_{r}$ it nearly a contutut.

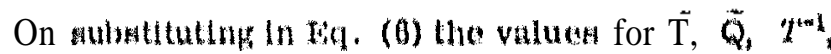

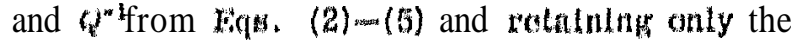
nigniticant torme wo get the following exproaston for 2k:

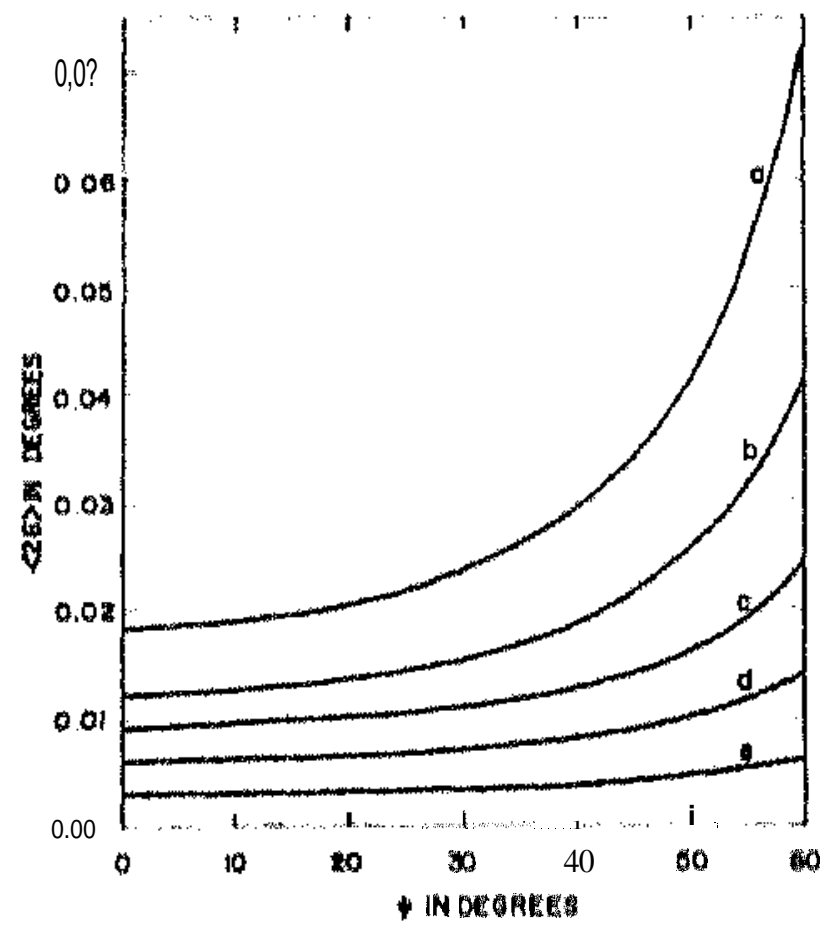

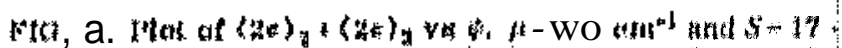

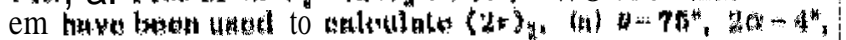

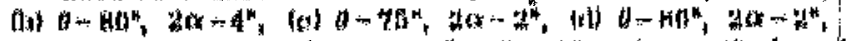

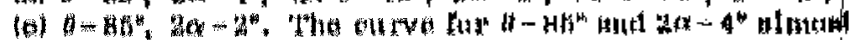
overlapt with (ti). 


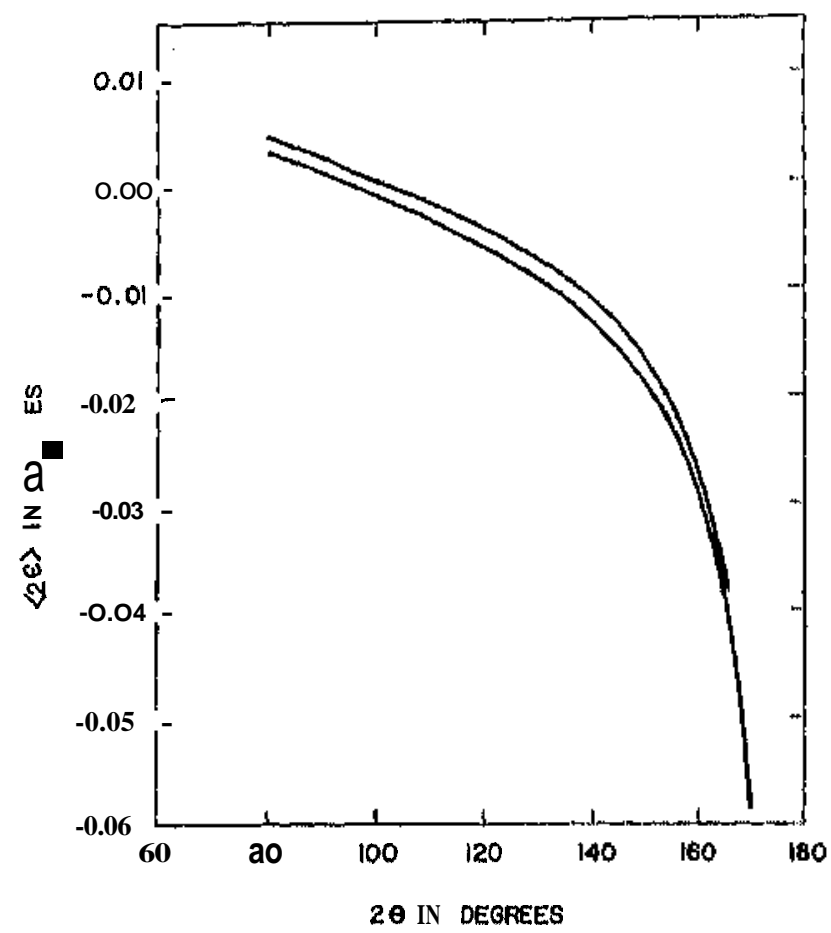

FIG. 4. Plot of $\langle 2 \epsilon\rangle_{\text {apia }}$ vs 20 tor $q=1.4$. Uppor curvo $\psi=0^{\circ}$. Lower curvo $\psi=3 ; 0^{\circ}$.

$$
\begin{aligned}
2 \epsilon & =\eta^{-1} S^{-1}\left\{x_{s}\left[\cos (\varphi-\psi)+\eta \cos (\varphi+\gamma(\varphi)]+y_{r}+\eta y_{s}\right\}\right. \\
& +S^{-2}\left[y_{s}^{2} \eta^{-1} \sin 2 \varphi-x_{f} y_{s} \sin (\varphi+\psi)-\eta^{-2} x_{r} y_{s} \sin (\varphi-\psi)\right] \\
& +\eta^{-1} S^{-2}\left\{z_{s}^{2}\left[1+\frac{1}{2}\left(\eta+\eta^{-1}\right) \cos 2 \varphi\right] \csc 2 \varphi+\frac{1}{2} z_{r}^{2} \eta^{-1} \cot 2 \varphi\right. \\
& +\frac{1}{2} z_{f}^{2} \eta \cot 2 \varphi-z_{r} z_{s}\left(1+\eta^{-1} \cos 2 \varphi\right) \csc 2 \varphi \\
& \left.+z_{r} z_{f} \csc 2 \varphi-z_{f} z_{s}(1+77 \cos 2 \varphi) \csc 2 \varphi\right\}_{s}
\end{aligned}
$$

where

$$
\eta=\sin (\theta-\psi) / \sin (\theta+\psi) \text {. }
$$

\section{HI. CENTROID SHIFT}

\section{A. Equatorial Terms}

We shall first consider the terms containing oquatorial components.

The terms $y_{r} / \eta S$ and $\mathrm{V}^{\mathrm{S}}$ yepresent the displacem ments due to finite width of the source and the 10ceiving slit. The axes of coordinates have been so chosen that

$$
\left\langle y_{j}\right\rangle=\left\langle y_{r}\right\rangle=0 \text {. }
$$

These terms therefore do not lead to any displacement of the centroid.

The term in $x_{s}$ leads to displacement due to various factors. These include (a) the displacement of the specimen surface from the axds of the diffractom- oter, (b) tilt of the specimen surface with the diffractomoteraxis, (c) mistittingr of I of the $2: 1$ rallo :und he valdillom of $z: 1 x:$ angle, and (d) the finite altworption of the s beam in the spoctursu.

The displacomont of the Huedmen murfas: diffractometor axts displaces cont rold of a tion line from its true postitom. The centre of a diffraction lino due to a dinplacement $l$ specimen surface from the axis is rivon by

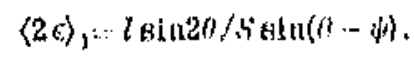

act ti sro ith

$t$ is taken to be posilive if the difremetomote Hos outerde the syedmen and nesitive othes

The thit of tho specimom with raspert to dilt oter axis does not lead to any displaksmurnt small broadontris. Simlarly, the mitsotedn

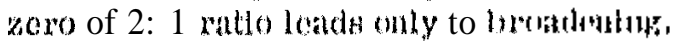

Duo to the finte aberplion of $x$ ripys In the

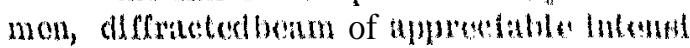
artso from the matertal bendith Het mreface

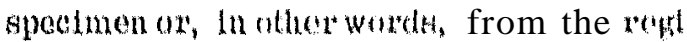

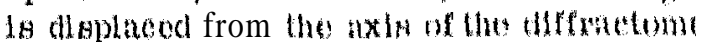
displacemont of the controtal cturesel by this $\mathrm{J}$

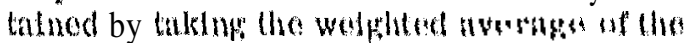
in $x_{s}$ in 15q, (7) and i $A$ givou by

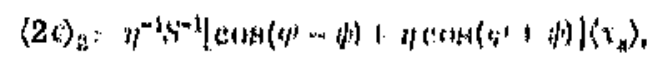

where

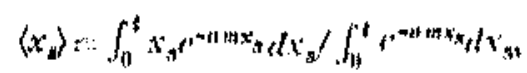

where 14 is the linear absorptlon soctherent

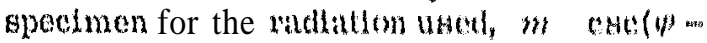

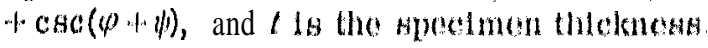

On evaluating tho integrultr, we not

$$
\left\langle x_{s}\right\rangle_{\ldots}\left(1-n m t\left(t^{n+m t}-1\right)^{-1} \mid / t m\right. \text {. }
$$

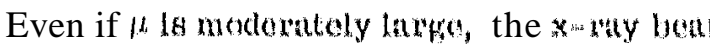
absorbed in tho Hpochenon within frictlonim ot: and thorofore the thicknows of the muscimen :

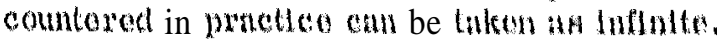
tonds toward inflully, tho Hosemel term lnotwes

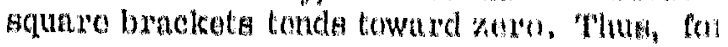
spechnen of infinite thleknoks, wo have

$$
\left\langle x_{*}\right\rangle: 1 / 1, m \text {. }
$$

On subatituting the valuo of $\left\langle r_{n}\right\rangle$ from $1+q$. (11) $(0)$, we get

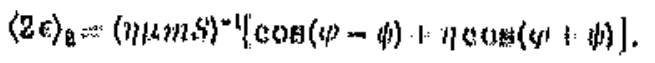

In case $\mu$ ta amall, $E q$, (10) Inatend of (11.) mi used for tho value of $\left\langle w_{s}\right\rangle$. Addithonal complien which axlso if the absorpllon coolftedentit var have been consldered by Mubexp, "We whall $n$ consider tha case as it la not commonly oncou tered in practice.

The shift of eentroid due to torm in $y_{s}^{a} 1 \mathrm{t}$ given $\left.\left.\langle 2 \Leftrightarrow\rangle_{9}=\eta^{-1}\right\}^{-B} \sin 2 \varphi\left\langle y^{2}\right\rangle\right\rangle$. the ac: lit ${ }^{\text {t5 }}$ se 


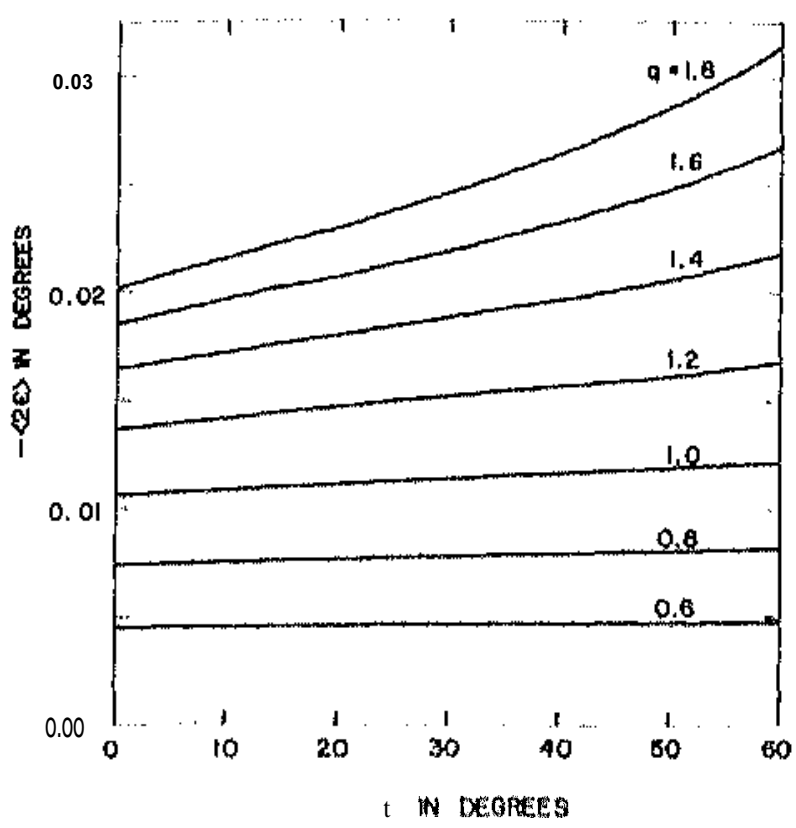

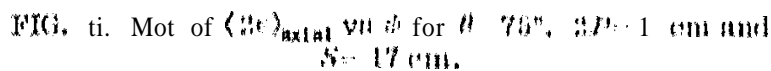

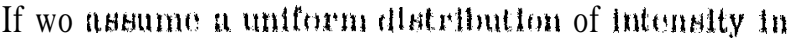
the primary lemm, them

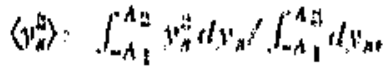

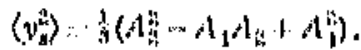

Since the equatorlal alvergence $2 x$ IH small, wo have

$$
A_{1}=A_{2} \sin / \sin (\varphi+4) \text {. }
$$

On substituthin: the vilues of $A_{1}$ and $A_{3,}$ wo pot

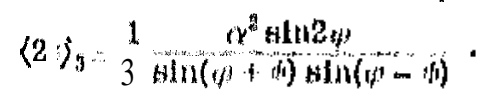

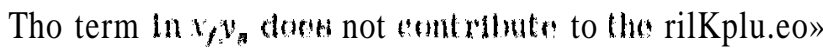
mont of controld alns the axis lwa beon HO clowen

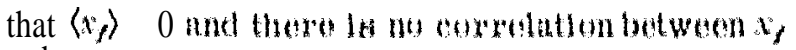
and $y_{n}$.

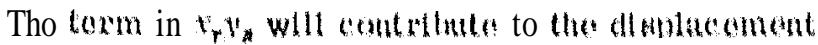

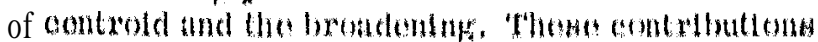
axhe due to the ftu-t that the conters of uxthelly of the

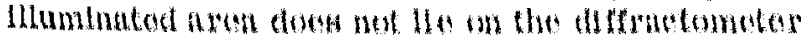

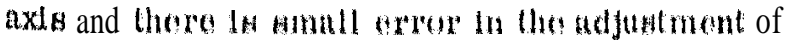
the postiton of the xesestatg Hitt on the detector arm,

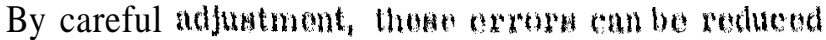
to about 0.1 tun. With these valuen, the displate to ment of the centetot whild bo low than

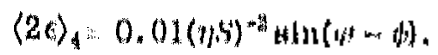

\section{B. Axtul Terms}

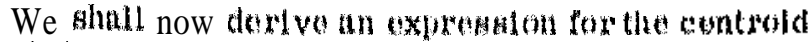

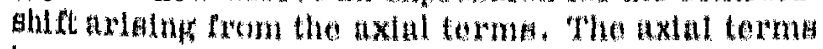
in Eq, (?) can bo senwritlen

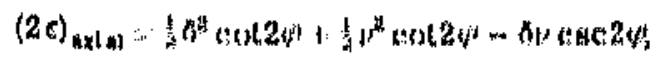

$$
\text { bi... }\left(x_{d}-z_{f}\right) / s
$$

and

$$
\nu . .\left(z_{r}-z_{s}\right) / n, s .
$$

6 and $v$ represent the angles which incident and the diffracted rays make with the equatorial plane. We shall consider the case of two soller slits, one in th the incident beam and the othor in the diffracted beam. The Sollet slits limit the maximum axial divergence to $A$ and reduce the intensity by a factor $(1-|8| / \Delta)$ of the rays which make an angle 6 with the equatorial plane; A is equal to the separation between the folls of the Sailer slite divided by the length of the foil.

The displacement of the controld is given by

$$
\langle 2 \theta\rangle_{2 \times 1+1}: N / n,
$$

whore

$$
N \cdot \iiint(2 \theta\rangle_{a x+a t}(1-|\delta| / \Delta)(1-|\nu| / \Delta) d \nu d \delta d b
$$

and

$$
\text { b. } \iiint(1-|\theta| / \Delta)(1-|v| / \Delta) d v d 6 d p \text {. }
$$

It IH surflciont ${ }^{\text {in }}$ to consider only tho posttive value of 0 with soth posttive and negative valuos for $\nu$. $f>$ Is identical with $z_{n}$. Following Plko, " wo Introdues a parameter $q$ which is deflned as

$$
\text { A.s: : } q{ }^{\prime}
$$

whore 27 is the axtal dinension of the spectmon. We whall confine our attention only to the ease in which the axial almonsions of the cocus, spectmen, and the rocolving sllt are all equal. In practice, one can turn the spocimon such that the surface normal

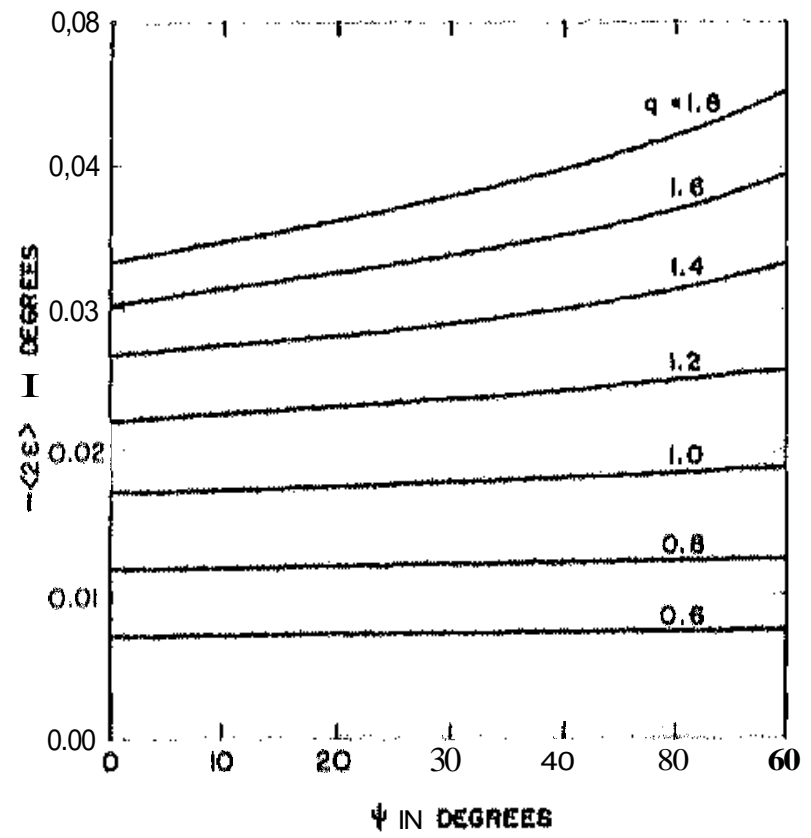

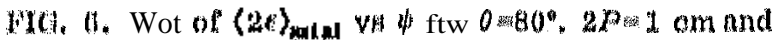
$5 \% 17 \mathrm{om}$. 


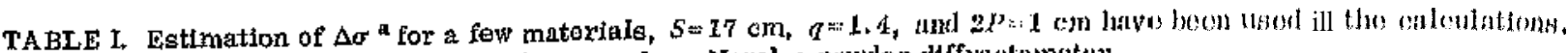
These values are for a Noroleo powdor diffutoliomotex.

\begin{tabular}{|c|c|c|c|c|c|c|c|c|c|}
\hline Material & $\begin{array}{c}\text { Radiation } \\
(h k l)\end{array}$ & $2 \theta^{\circ}$ & $2 \alpha^{\circ}$ & $\begin{array}{r}T_{(0-45)} \\
\mathrm{ksi} /{ }^{\circ} \Delta 20\end{array}$ & $\langle 2 \epsilon\rangle_{0}-\langle 2 \epsilon\rangle_{15}$ & $\Delta\left(T^{\prime}\right.$ & 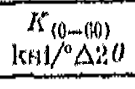 & $\langle 2 c\rangle_{0}=\langle 2 \theta\rangle_{i}$ & $\Delta r$ \\
\hline Steel AISI 4340 & $\underset{(211)}{\operatorname{Cr} K \alpha}$ & 156 & $\begin{array}{l}4 \\
1\end{array}$ & 120 & $\begin{array}{l}-0.0073 \\
+0.0029\end{array}$ & $\begin{array}{l}-0.8760 \\
+0.3480\end{array}$ & $\mathrm{HO}$ & 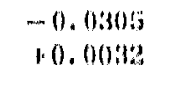 & $\begin{array}{l}* 4.4100 \\
+0.24000\end{array}$ \\
\hline $\begin{array}{l}\text { Titanium alloy } \\
\mathrm{Ti}-6 \mathrm{Al}-4 \mathrm{~V}\end{array}$ & $\begin{array}{l}\mathrm{Cu} X \alpha \\
(2133)\end{array}$ & 150 & & 70 & $\begin{array}{l}-0.0111 \\
+0.0021\end{array}$ & $\begin{array}{l}-0.7770 \\
+0.1680\end{array}$ & 47 & $\begin{array}{l}-0.01112 \\
+0.0017\end{array}$ & $\begin{array}{r}\text { As. } 1711 \\
+0.0790\end{array}$ \\
\hline $\begin{array}{l}\text { Aluminum alloy } \\
7079-T 611\end{array}$ & $\begin{array}{c}\operatorname{CrKK\alpha } \\
(311)\end{array}$ & 140 & $\begin{array}{l}4 \\
1\end{array}$ & 11 & $\begin{array}{r}-0.0198 \\
+0.0010\end{array}$ & $\begin{array}{l}-0.9900 \\
+0.0500\end{array}$ & 33 & $\begin{array}{l}=0.0924 k \\
-0.0020\end{array}$ & $\begin{array}{l}3.01992 \\
0.019697\end{array}$ \\
\hline $\begin{array}{l}\text { Aluminum alloy } \\
7079-\mathrm{T} 611\end{array}$ & $\frac{\mathrm{CuK \alpha}}{(333)}$ & 162 & & - & $\begin{array}{l}-0.0046 \\
+0.0028\end{array}$ & $\begin{array}{l}-0.0900 \\
+0.0560\end{array}$ & 1.1 & $\begin{array}{r}-0.01104 \\
10.00 .10\end{array}$ & 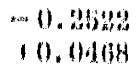 \\
\hline
\end{tabular}

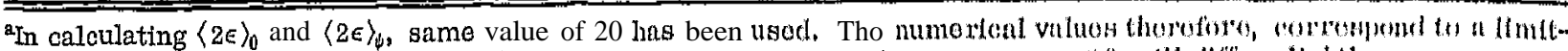
ing case when the specimen is stress free. In tho prosonco of any stross, 200 und $20_{\phi}$ whll affor Hilthy.

moves either towards the source (as shown in Fig. 1) or away from it; the position of the receiving slit moves respectively closer to or farther from the diffractometer axis. For various practical reasons, the former setting is chosen. This gives $\eta \leqslant 1$. We shall, therefore, consider only $\eta \leqslant 1$ in the further discussions. The expressions for $\langle 2 \epsilon\rangle_{a \times 1 \mathrm{al}}$ for the various cases are given in the Appendix.

\section{DISCUSSION}

The total displacement of the centroid of a diffraction line is given by the sura of the displacements duo to the various torms in lift. (7). Ammor tho contributions ardsing from tho equatorlal tormm, $\langle 2 c\rangle_{1}$ and $\langle 2 \epsilon\rangle_{1}$ can bo made noplipithle by the propere adjustment of tho spodimen and diffractometer. Tho maln soures of deplacoment of the controld nee then, the spectmon transparency and the diverpence

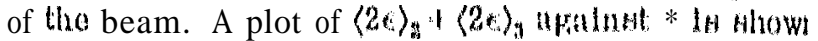

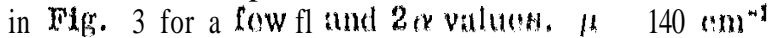
and $5: 17$ om have boon utod in the commutattom of $\langle 2 \epsilon\rangle_{2}$. Both $\langle 2 \epsilon\rangle_{2}$ and $\langle 2 \varepsilon\rangle_{9}$ ato poultuva and therofore the total displacemont is towurtUt low a vilue. Since 14 occuxs in the denominator [Kq. (12),$\langle 2 n\rangle_{g}$ be-

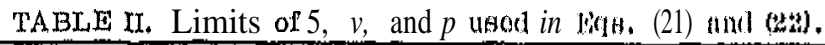

$$
0 \leq \delta \leq(p+p) / S
$$

$0 \leqslant \delta \leqslant(P+p) / S$ $0 \leq \delta \leq(P+p) / S$ $0 \leq \delta \leq(P+p) / S$

$0 \leq \delta \leq(P+p) / S$

$0 \leq \delta \leqslant(P+p) / S$

$0 \leq \delta \leq(P+p) / s$

$0 \leq \delta \leq(P+p) / S$

$0 \leq \delta \leq(P+p) / S$

$0 \leq \delta \leq(P+p) / S$

$0 \leq \delta \leq \Delta$

$0 \leq \delta \leq(P+p) / S$

$0 \leq \delta \leq(P+P) / S$

$0 \leq \delta \leq(P+p) / S$

$0 \leq \delta \leq \Delta$

$0 \leq \delta \leq(P+p) / S$

$0 \leq \delta \leq(P+p) / s$

$0 \leq \delta \leq \Delta$

$0 \leq \delta \leq \Delta$

\section{(I) $q$ a 2 and $\gamma / q=2$}

$-p \leqslant p=1 \cdot p$

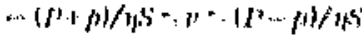

(II) $q \geq 2$ and $1 \approx \eta q=2$

$-P \leq p \leq P(1-\eta q)$

$P(1-\eta q)=p)-P(1-\eta w)$

$-p(1-\eta q)=p \leq p$

$=(f+\mu) / 25-1) \mathrm{A}$

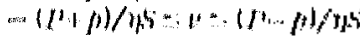

$\Delta+\nu,(l) \cdots(j)+n$

(III) $q \geq 2$ and $\eta q \mathrm{~s} 1$

$$
\begin{aligned}
& -p \leq p-p(1-\eta q) \\
& -p(1-\eta q) \leq l=1 p(1-1 \phi) \\
& p(1-\eta \phi)=i p \leq 1 p
\end{aligned}
$$

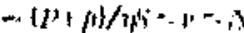

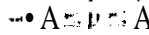

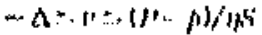

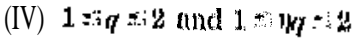

$-p=s p \leq p(1-m)$

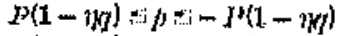

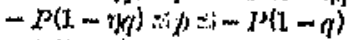

$-P(1-q)=p=i \omega$

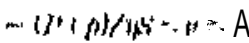

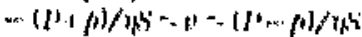

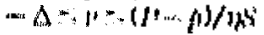

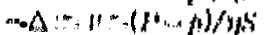

(V) $1 \leq q \leq 2, n q \pm 1$ and $(q+\eta q)$ है 2

$$
\begin{aligned}
& -p \leq p \leq x-p(1-\eta k) \\
& -P(1-n g)=1 p=l^{2}(1-\eta t) \\
& P(1-n q) \text { at } p=P(1-q) \\
& -P(1-q)=p
\end{aligned}
$$

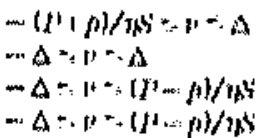

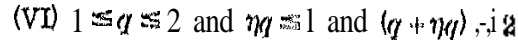

$$
\begin{aligned}
& -P \leq p \leq-P(1-m) \\
& -P(1-n q)=i p=-P(d-q) \\
& -p(1-q)=p(1-p) \\
& p\left(\lambda-m_{C}\right)=\rho \rho
\end{aligned}
$$

(VII) $q: 1$ and $x Y$ : 


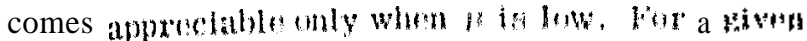

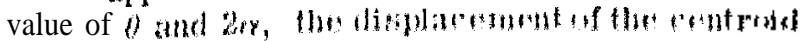

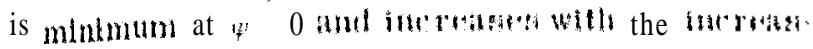
tng value of is.

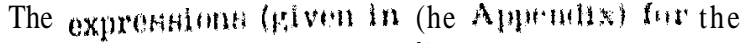

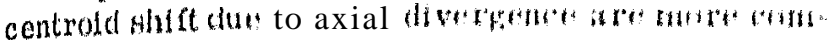

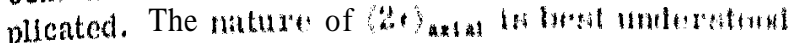

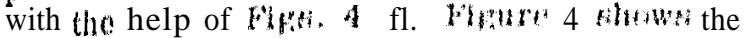

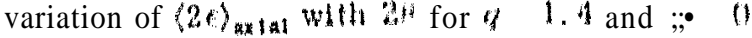

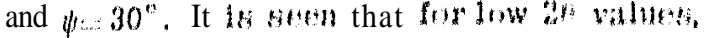

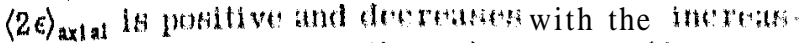

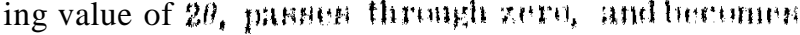

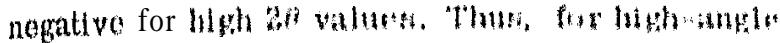
reflections which are montly usked in all restes sumb

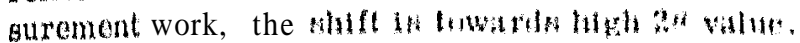

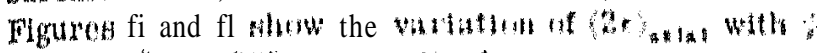

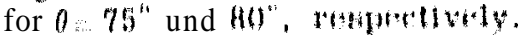

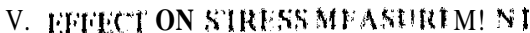

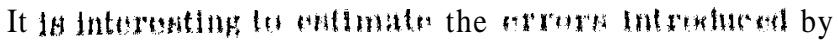

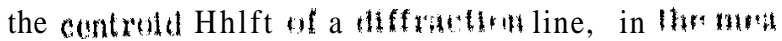

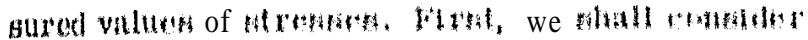

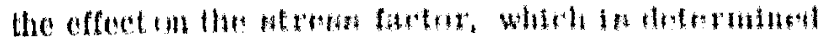

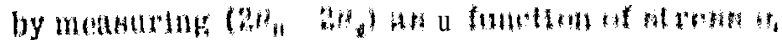

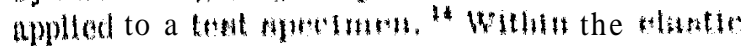

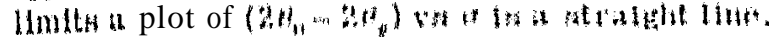

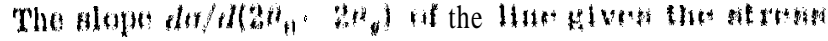

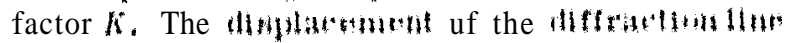

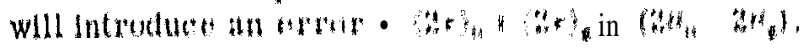

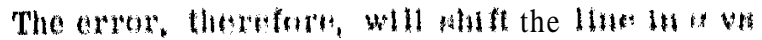

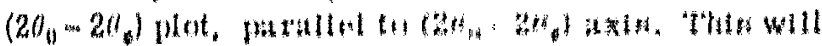

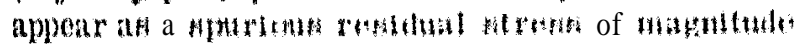

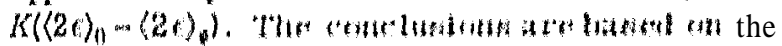

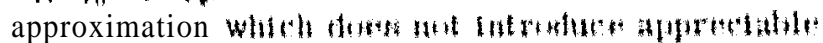

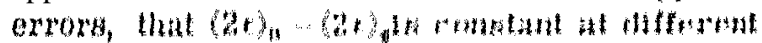

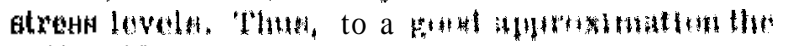

determination of $k$ is not affectodhy the centrobl whift.

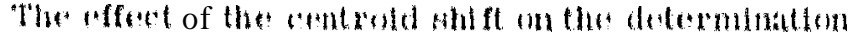
uf atresise is butels that

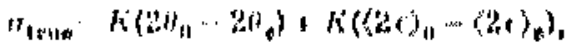

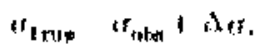

Fur a fow materials, Ao has bern estimated and results ato summatreed in 'Table 1, It is sem that

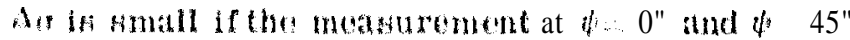
at" mate and 2 ar is 1".

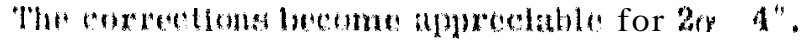

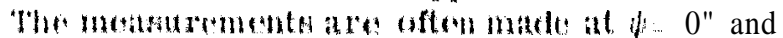

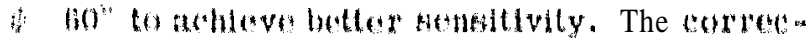

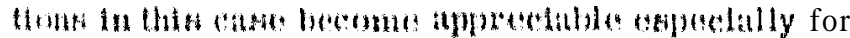
tti».

\section{$\operatorname{con} 1.1 \mathrm{sin}$}

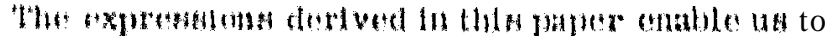

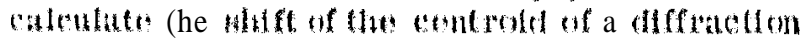

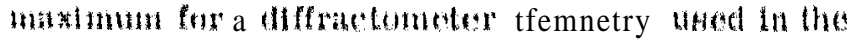

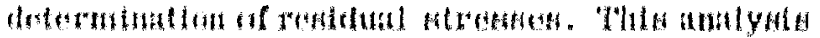

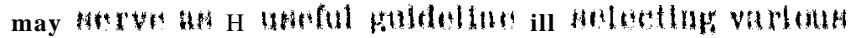

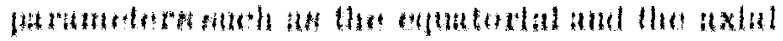

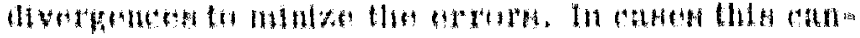

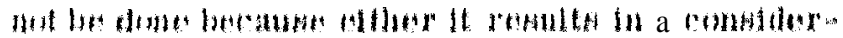

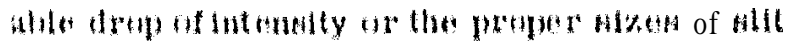

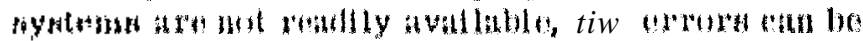

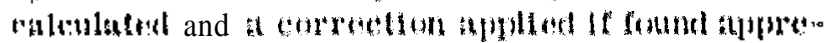
itatilia.

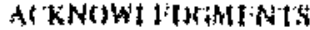

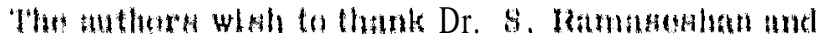

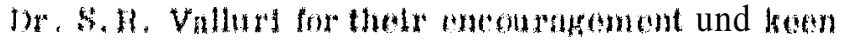
tatwrest in the work.

\section{AltiNinX}

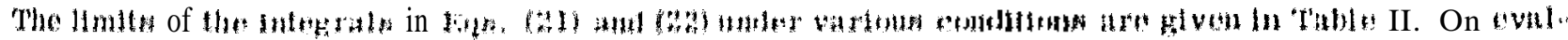

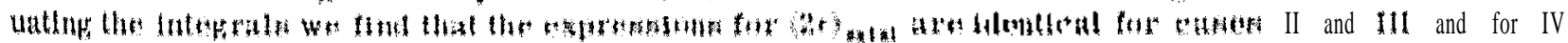

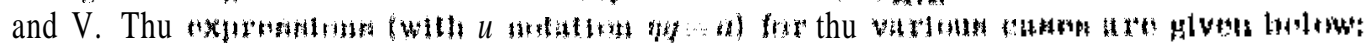

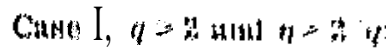

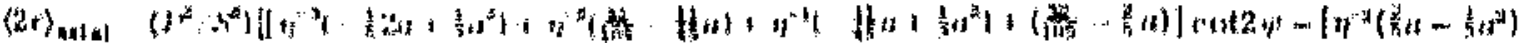

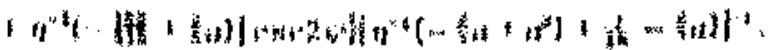

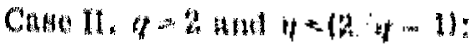

$$
\begin{aligned}
& \text { (20) ant } 0 \text { ( }
\end{aligned}
$$

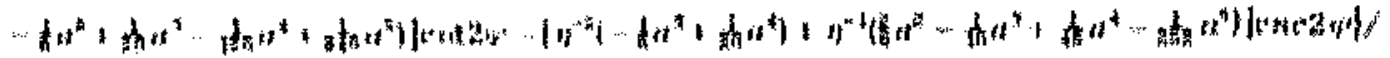

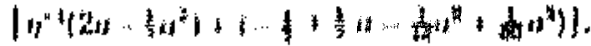

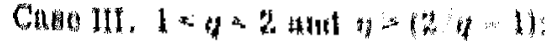

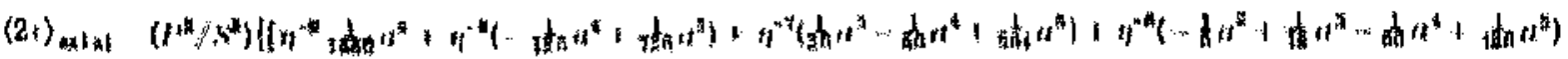

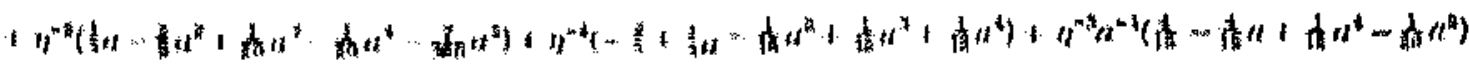

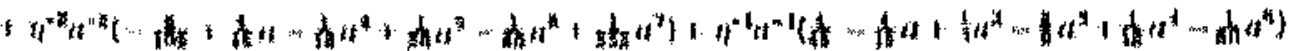

$$
\begin{aligned}
& \text { 1. } a^{n+2} \text { ( }
\end{aligned}
$$




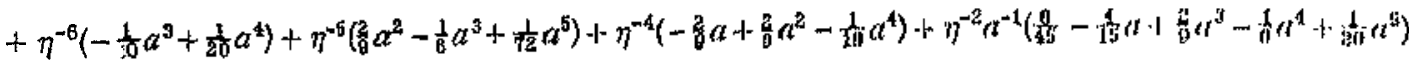

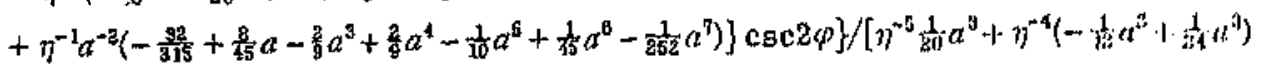

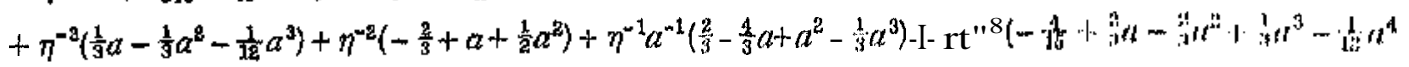

$$
\begin{aligned}
& \left.\left.+\frac{1}{60} a^{5}\right)\right] \text {. }
\end{aligned}
$$

ise IV. $q \leqslant 2$ and $\eta \leqslant(2 / q-1)$ :

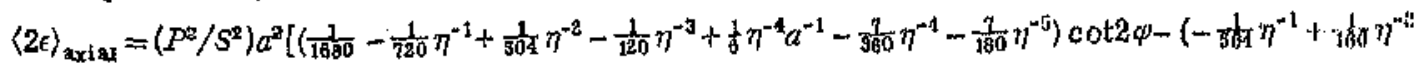

$$
\begin{aligned}
& \left.\left.-\frac{1}{\eta 2} \eta^{-4}\right) \csc 2 \varphi\right] /\left[\frac{1}{120}-\frac{1}{24} \eta^{-1}+\eta^{-2} a^{-2}-\frac{1}{2} \eta^{-2}-\frac{1}{2} \eta^{-3}\right] \text {. }
\end{aligned}
$$

The aberrations caused by spectral dispersion, refraejon, and variation of response with wavelength have not jeen considered.

R. C. Spencer, Phys. Rev. 55, 239 (1939).

R. C. Spencer, J. Appl, Phys. 20, 413 (1949).

L. Alexander, J. Appl. Phys. 21, 126 (1950).

L. Alexander, J. Appl. Phys. 25, 155 (1954).

L. Alexander, J. Appl. Phys. 19, 1068 (1948).

L. Alexander, Brit. J. Appl. Phys. 4, 92 (1953). A.J. C. Wilson, J. Sci. Instr, 27, 327 (1950). In stress measurement work peak of a diffraction line is taken as a measure of position. The displacement of the peak to a first approximation is same [A. J, C. Wilson, Proc. Phys. Soc. (London) 78, 249 (1961)] as that of the centroid. The physical aberrations which are not diseussed in this paper may offoct the prak and the cont robl qutte difforently (Rof. 13).

${ }^{0} J$. N. Iatabrook, Brit. ,T. Appl, Mhyn. *, \#ts (1)tia).

${ }^{10}$ L. R. Pike, J. Sol. Insts, :»4, :16\% (1967).

11J. Y. Langford, J. Sat. Inutt: nil, fits (1!16\%).

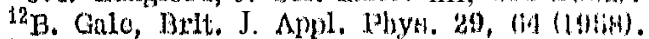

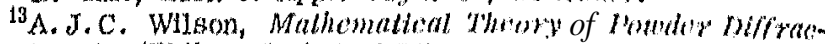

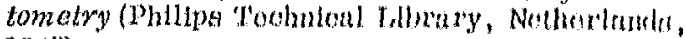
196ㄱ).

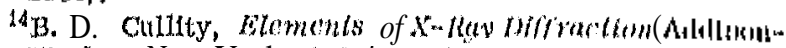
Wosloy, Now York, 1, (16)), p. 4 it1.

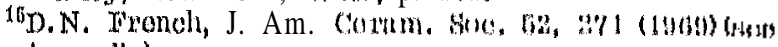
Appondix).

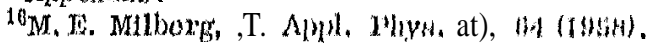

